\title{
Physical Studies of Foamed Rubber Composites I-The Mechanical Properties of foamed EPDM Rubber
}

\author{
A.M.Y El. Lawindy, K.M.Abd El-Kader, W.E. Mahmoud and \\ *H.H.Hassan, \\ Department of Physics, Faculty of Science, Suez Canal University, \\ Ismailia, Egypt \\ * Department of Physics, Faculty of Science, Cairo University, Giza, \\ Egypt
}

\begin{abstract}
Foamed ethylene propylene diene terpolymer (EPDM) was compounded with azo dicarbonamide $(A D C / K)$ as a foaming agent. The mechanical properties, under compression and extension, were measured at different temperatures. It was found that the increase of foaming agent concentration affects markedly all the mechanical parameters. The increase in the foaming agent concentration decreases monotonically the tensile strength, $\sigma_{f}$, and failure strain $\varepsilon_{f}$.
\end{abstract}




\section{Introduction}

Foamed rubber is now widely used in different technological applications. The preparation technology attracts the interest of many authors [1-9].

Although the foamed rubber is widely manufactured and serviceable all over the world, the available articles concerning the electrical, mechanical and physico-mechanical properties are few. In fact, the description of these new materials having specific physical properties has been mainly empirical, because no exact theory is currently known that relates macroscopic properties of multiphase composites to their microscopic structure.

The correlation between experimental data in both states of reinforced rubber and foamed rubber is attractive from the experimental and theoretical point of view.

The effect of reinforcing fillers such as carbon black, carbon fiber, silicate,...etc. on the physical properties of rubber composites are extensively studied experimentally and theoretically [10-18].

On the other hand, the addition of foaming agent to rubber composites will certainly affect their microscopic structure which will be reflected on their mechanical, electrical, physico-mechanical...etc. properties of foamed composites.

We embarked on a program to study some physical properties of foamed rubber. EPDM rubber, has been chosen, in the present study, due to its wellknown chemical stability, good aging resistance and high resistance to break down during mechanical operations, especially those which generate shear. It also a general-purpose rubber. EPDM was compounded with different concentrations of $\mathrm{ADC} / \mathrm{K}$, (Bayer) foaming agent to obtain foamed $\mathrm{EPDM}$ rubber composites.

The mechanical properties in both extension and compression such as elasticity modulus, E, tensile strength, $\sigma_{\mathrm{f}}$, strain at break, $\varepsilon_{\mathrm{f}}$, and the degree of compressibility were calculated.

Continium mechanics theory for compressible material [19-21], was tested to produce the initial shear modulus of these foams. The dependence of the relative elasticity on the volume fraction of the foaming agent was also investigated. 


\section{Experimental Technique}

The foamed EPDM rubber composites were compounded according to the recipe shown in Table 1, using a two-roll mill. The ingredients were added in the same order as listed.

Table (1) : Ingredients of the investigated foamed EPDM rubber composites. MBTS is dibenzthiazyl disulphide, PBN is phenyl- $\beta$-naphthyl amine, and phr is part per hundred part of rubber by weight.

\begin{tabular}{|l|c|c|c|c|}
\hline \multicolumn{5}{|c|}{ Samples Name } \\
\hline Ingredient (phr) & WE0 & WE5 & WE10 & We15 \\
\hline EPDM & 100 & 100 & 100 & 100 \\
\hline Stearic acid & 2 & 2 & 2 & 2 \\
\hline Zinc Oxide & 5 & 5 & 5 & 5 \\
\hline HAF & 50 & 50 & 50 & 50 \\
\hline Processing Oil & 15 & 15 & 15 & 15 \\
\hline MBTS & 2 & 2 & 2 & 2 \\
\hline PBN & 1 & 1 & 1 & 1 \\
\hline Sulfur & 2.5 & 2.5 & 2.5 & 2.5 \\
\hline
\end{tabular}

The specifications of the used two roll mill are as follows: length: $30 \mathrm{~cm}$, radius: $15 \mathrm{~cm}$, speed of slow roll: $18 \mathrm{rpm}$ and gear ratio: 1.4 . The samples are vulcanized under a heating press (KARL KOLB, Germany) under a pressure of $\mathrm{P}=0.40 \mathrm{MPa}$, and temperature of $\mathrm{T}=150{ }^{\circ} \mathrm{C}$. The compounded rubber was left for $24 \mathrm{hr}$ before vulcanization. The optimum vulcanisation time was fixed at $\mathrm{t}=$ 30 minutes. The vulcanized samples were shelf aged for 48 hours before testing.

The measured apparent densities in $\mathrm{kg} / \mathrm{m}^{3}$ are $1150 \pm 110,860 \pm 100$, $611 \pm 30$ and $435 \pm 50$ for samples $\mathrm{W} 0, \mathrm{~W} 5, \mathrm{~W} 10$, and $\mathrm{W} 15$ respectively.

The samples used in extension test are strips of dimension $2 \times 0.3 \times 0.2$ $\mathrm{cm}^{3}$, whereas samples used in compression test are of cylindrical shape of cross sectional area $=1.13 \mathrm{~cm}^{2}$ and length $=1 \mathrm{~cm}$. Material tester (AMETEK, USA) was facilitated. A motor with a micro switch, as an attachment, was used to measure the strain at a resolution of $0.1 \mathrm{~cm}$. A digital force gauge (Accu force, USA) of $50 \mathrm{~N}$ capacity was used to measure stresses.

In extension experiment the strain rate was $1.2 \mathrm{~mm} / \mathrm{min}$. In compression experiment strain rate was $0.4 \mathrm{~mm} / \mathrm{min}$. Compression test was limited to strain of $60 \%$ due to the limited capacity of the force gauge. 


\section{Results and Discussion}

Figures 1 and 2 represent the true stress vs. true strain under extension for vulcanizates containing different concentrations of foaming agent, $\mathrm{C}_{\mathrm{f}}(\mathrm{phr})$, at different temperatures for extension and for compression, at room temperature, respectively.
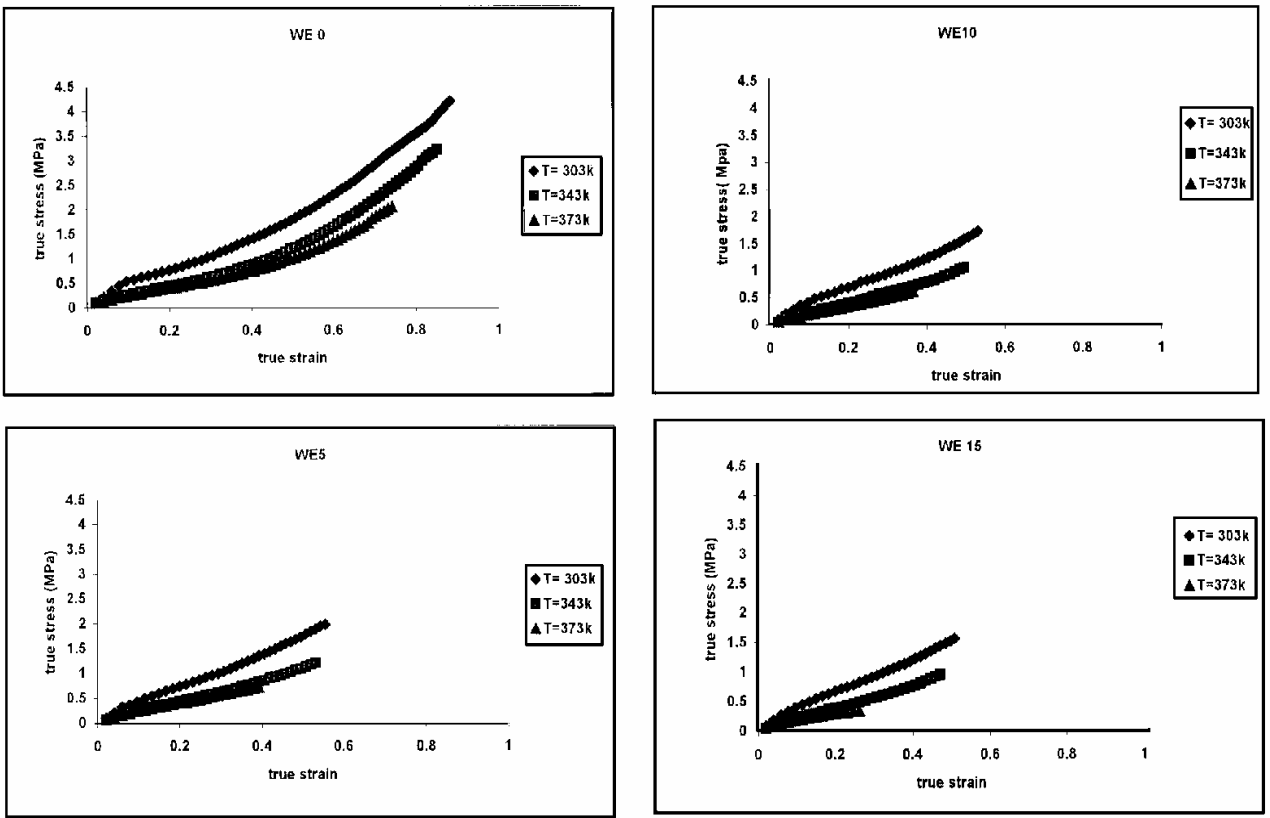

Fig. (1) True stress vs true strain under extension at, $30^{\circ} \mathrm{C}, 70^{\circ} \mathrm{C}$ and $100^{\circ} \mathrm{C}$, for samples W0, W5, W10 and W15.

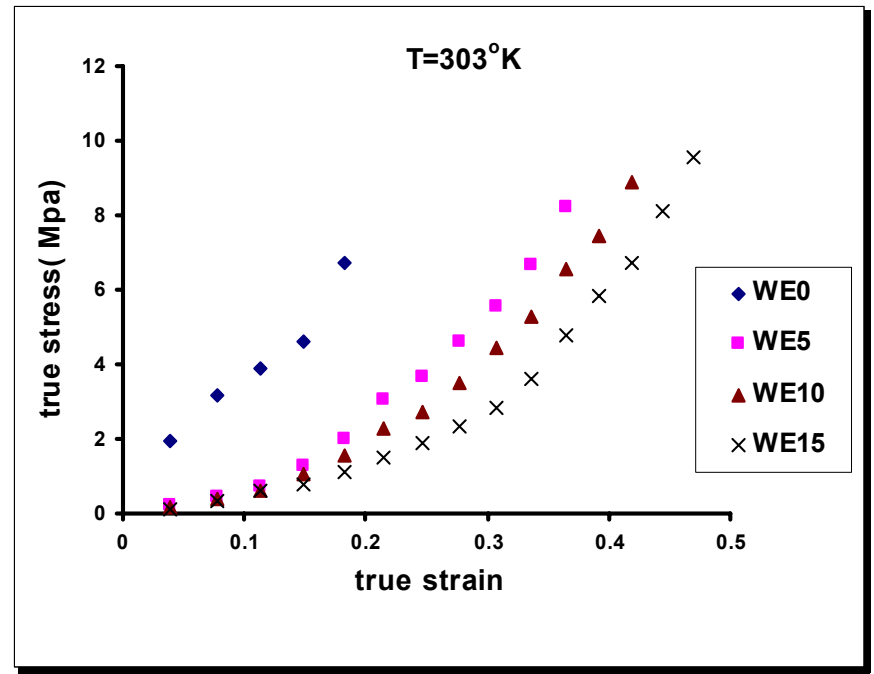

Fig. (2) True stress vs true strain under compression at, $30^{\circ} \mathrm{C}$ for the investigated samples. 
The deduced mechanical parameters; modulus of elasticity, E, strength, $\sigma_{\mathrm{f}}$, elongation at break, $\varepsilon_{\mathrm{f}}$, in both extension and compression, at room temperature, $30^{\circ} \mathrm{C}$, are presented in Table 2 . E was calculated as the slope of the true stress-true strain curves at low strains. Also $\sigma_{\mathrm{f}}$ was defined relative to the deformed dimension.

Table (2): The mechanical parameters of the investigated samples at room temperature $30^{\circ} \mathrm{C}$.

\begin{tabular}{|l|c|c|c|c|}
\hline & \multicolumn{3}{|c|}{ Extension } & Compression \\
\hline Sample & E (MPa $)$ & $\sigma_{\mathrm{f}}(\mathrm{MPa})$ & $\varepsilon_{\mathrm{f}}$ & E(MPa) \\
\hline W0 & 5.68 & 4.19 & 0.88 & 6.58 \\
\hline W5 & 5.37 & 1.97 & 0.55 & 6.15 \\
\hline W10 & 4.44 & 1.72 & 0.53 & 5.24 \\
\hline W15 & 4.19 & 1.56 & 0.50 & 4.84 \\
\hline
\end{tabular}

The effect of temperature on the above mechanical parameters is illustrated in Figure 3, for extension data. It is observed that all these parameters are monotonically decreasing upon increasing both foaming agent concentration and / or temperature.

One may explain such behavior in the following way: The density of gas bubbles inside the rubber matrix increases upon the increase of foaming agent concentration, whereas its volume is enlarged by thermal expansion effect. This will affect the volume fraction, $\phi_{c}$, of carbon black as reinforcing filler for the rubber matrix. In other words this dilution of carbon black will lower, the reinforcement of rubber matrix and consequently the samples become more brittle.

In order to obtain an empirical relation describing the dependence of the volume fraction of carbon black, $\phi_{c}$, on the concentration of foaming agent, $C_{f}$, one may suggest an ideal and simple model as follow:

Let us consider the volume fraction of carbon black in the unfoamed sample, $\phi_{c}^{o}$, as

$$
\phi_{c}^{o}=\frac{V_{c}}{V_{t}}=\frac{m_{c} / \rho_{c}}{m_{t} / \rho_{t}}
$$

where $V_{c}, m_{c}, \rho_{c}$ and $V_{t}, m_{t}, \rho_{t}$ are the volume, mass, and density for carbon and rubber matrix respectively. 

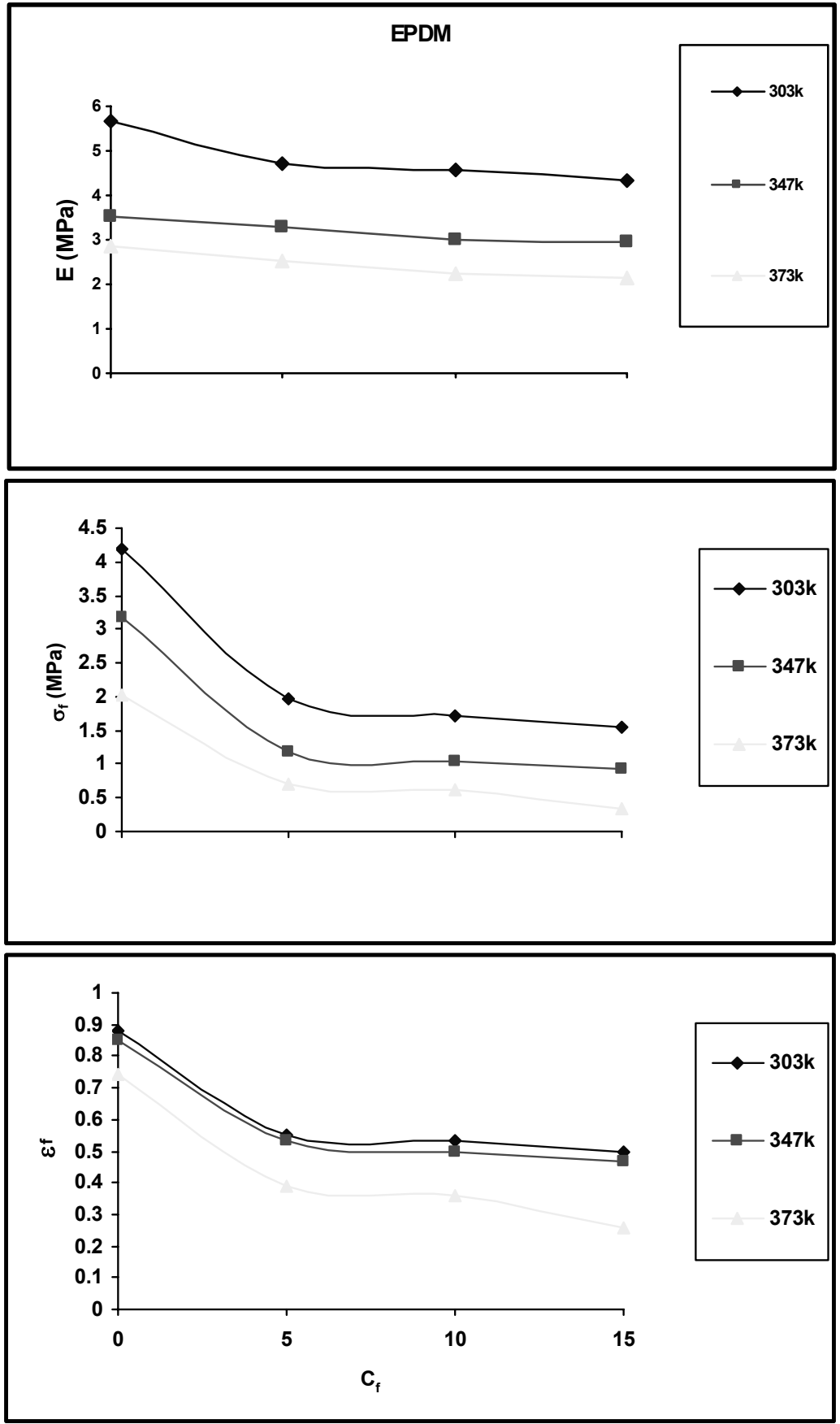

Fig. (3) The deduced mechanical parameters for the investigated sample under extension. 
Substituting for $m c=50 \mathrm{~g}, \rho_{c}=1.8 \mathrm{~g} / \mathrm{cm}^{3}, m_{t}=177.4 \mathrm{~g}, \rho_{t}=1.24 \mathrm{~g} / \mathrm{cm}^{3}$, all measured experimentally except $\rho_{c}$, one obtains $\phi_{c}{ }^{\circ} \simeq 0.19$.

The relation between the volume fraction of carbon black for foamed, $\phi_{c}$, and unfoamed, $\phi_{c}^{o}$ could be expressed as:

$$
\phi_{c}=\frac{\rho_{f}}{\rho_{t}} \phi_{c}^{o}
$$

where $\rho_{f}$ is the measured apparent density of the foamed sample.

The calculated values of $\phi_{c}$ as a function of foaming agent concentration $\mathrm{C}_{\mathrm{f}}$ was found to fit a linear relation of the form

$$
\phi_{c}=\phi_{c}^{o}-n C_{f}
$$

where $n=0.008(\mathrm{phr})^{-1}$ is a fitting constant. The fitting linear correlation coefficient was found $\mathrm{R}^{2} \sim 0.99$. In the rest of the discussion foaming agent was then considered as non-reinforcement filler.

In the case of uniaxial extension, continium mechanics theory, [19-21] predicts, for compressible material, the following equation;

$$
\frac{\sigma}{2\left(\lambda-\left(V / V_{o}\right) \lambda^{-2}\right)}=\frac{c_{2}}{\lambda}\left(V / V_{0}\right)+c_{1}
$$

where $\sigma$ is the nominal stress, $V$ and $V_{o}$ are the deformed and undeformed sample volume respectively, $2\left(c_{1}+c_{2}\right)=\mathrm{G}_{\mathrm{M}}$ is the shear modulus and $\lambda$ is the extension ratio. This equation is the analogue of Mooney- Rivlin equation [22] for incompressible materials.

Following Mooney- Rivlin, equation (3) was tested to calculate the shear modulus, $\mathrm{G}_{\mathrm{M}}$, where $c_{1}$ is the intercept of the left hand side drawn as a function of $\left(V / V_{o}\right) / \lambda=1 / \Lambda$ in the region of 0.88 to 1.0 , at $1 / \Lambda=0$ and $c_{2}$ is its slope. Figure 4 shows such fitting. The fitting correlation is $\cong 0.99$. 

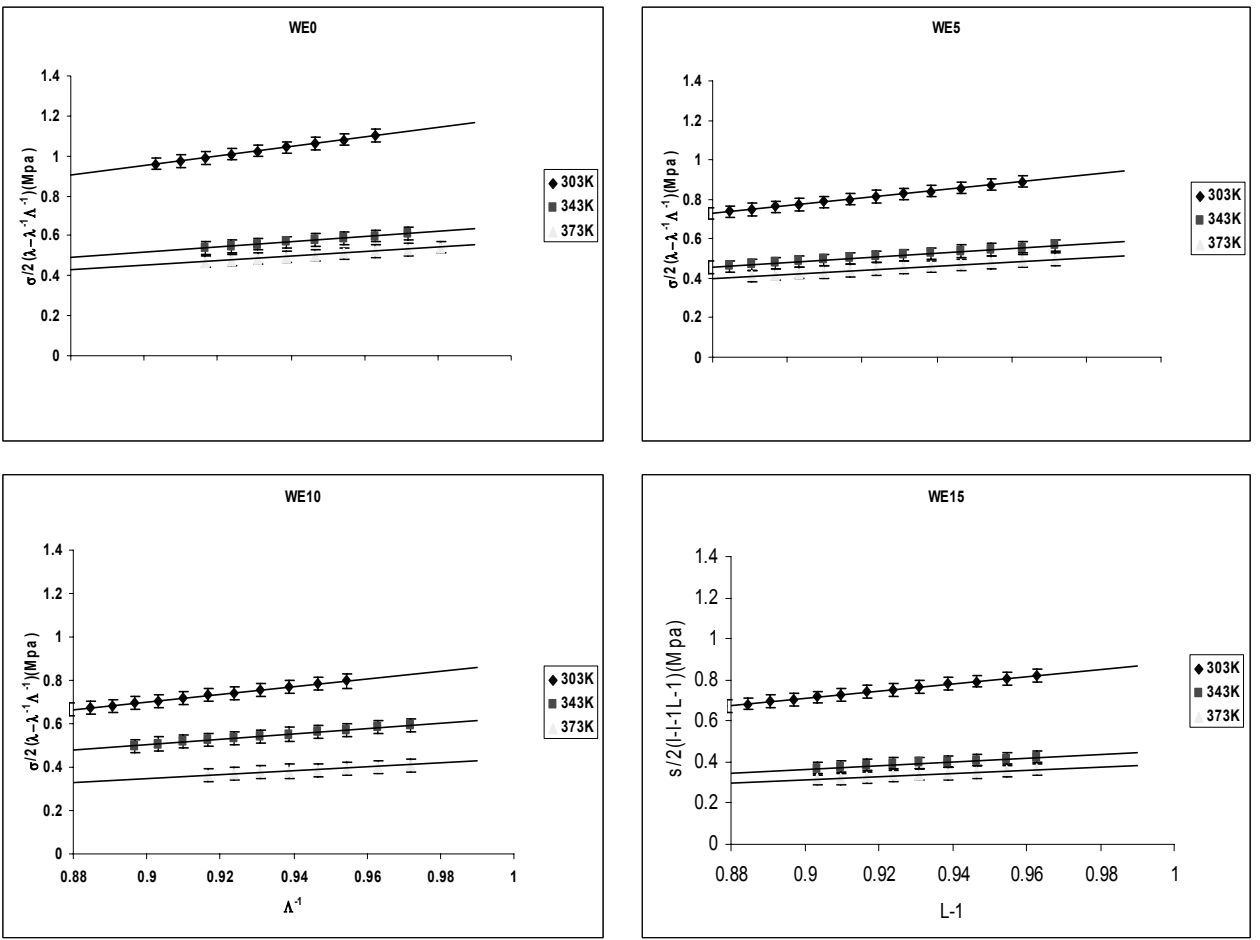

Fig. (4) The variation of $\frac{\sigma}{2\left(\lambda-\left(V / V_{o}\right) \lambda^{-2}\right)}$

vs $1 / \Lambda$ in the region 0.88 to 1.0 for extension data.

The Poisson's ratio, $v$, is found to be $\simeq 0.25 \pm 0.03$, from experiment of extension and zero for compression. The variation of the apparent modulus of elasticity, $G_{k}=E / 2.5$, for extension, as a function of the concentration of foaming agent, $\mathrm{C}_{\mathrm{f}}$, is shown in Figures 5 , in comparison with the obtained values of $\mathrm{G}_{\mathrm{M}}$, at different temperatures. An excellent consistency is observed.

For uniaxial compression case, Rivlin and Saunders[23], and Treloar [24] had shown that $c_{2}$ of equation (3) is not a constant and the correct expression would have to be;

$$
\sigma=2 c \cdot\left(\lambda-\frac{1}{\lambda^{2}}\right)
$$

where $\mathrm{c}$ is a constant. 

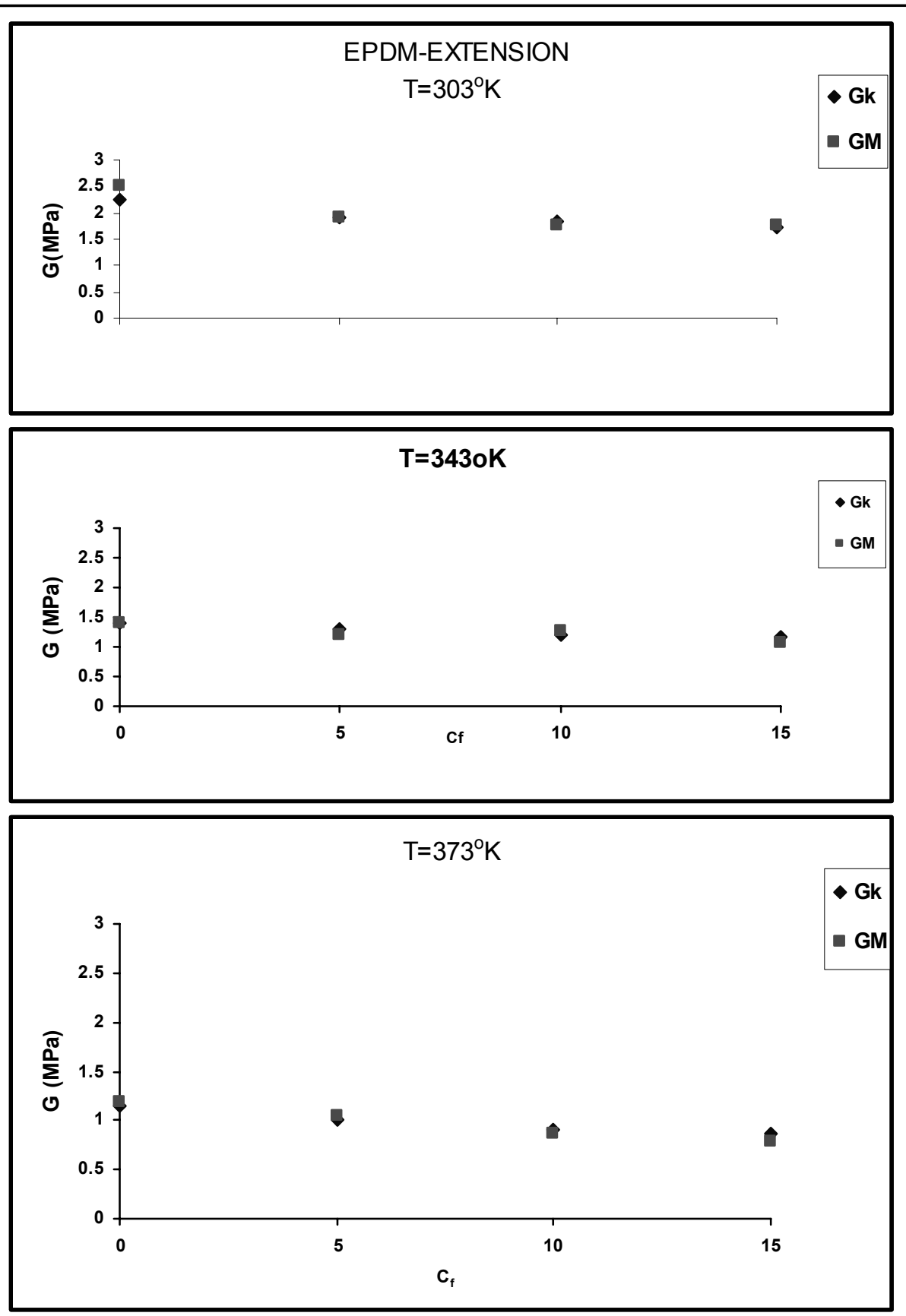

Fig. (5) The variation of $G_{k}$ and $G_{M}$ as a function of foaming agent concentration, $\mathrm{C}_{\mathrm{f}}$, at different temperature 30,70 and $100^{\circ} \mathrm{C}$ respectively under extension. 
The compression data were fitted to this equation, and found that it is not fulfilled. The compression data were found to fit an equation of the form;

$$
\sigma=2 c \cdot\left(\lambda-\frac{1}{\lambda^{2}}\right)-\mathrm{B}
$$

where $B$ is a constant. It was found that $B$ increases, by increasing the foaming agent concentration, Figure (6), and $2 c=\mathrm{G}_{\mathrm{c}}$, produces the obtained shear modulus, $G_{k}$, values previously obtained for foamed samples. A comparison between $G_{c}$ and $G_{k}$, Figure (7), shows a fair consistency.

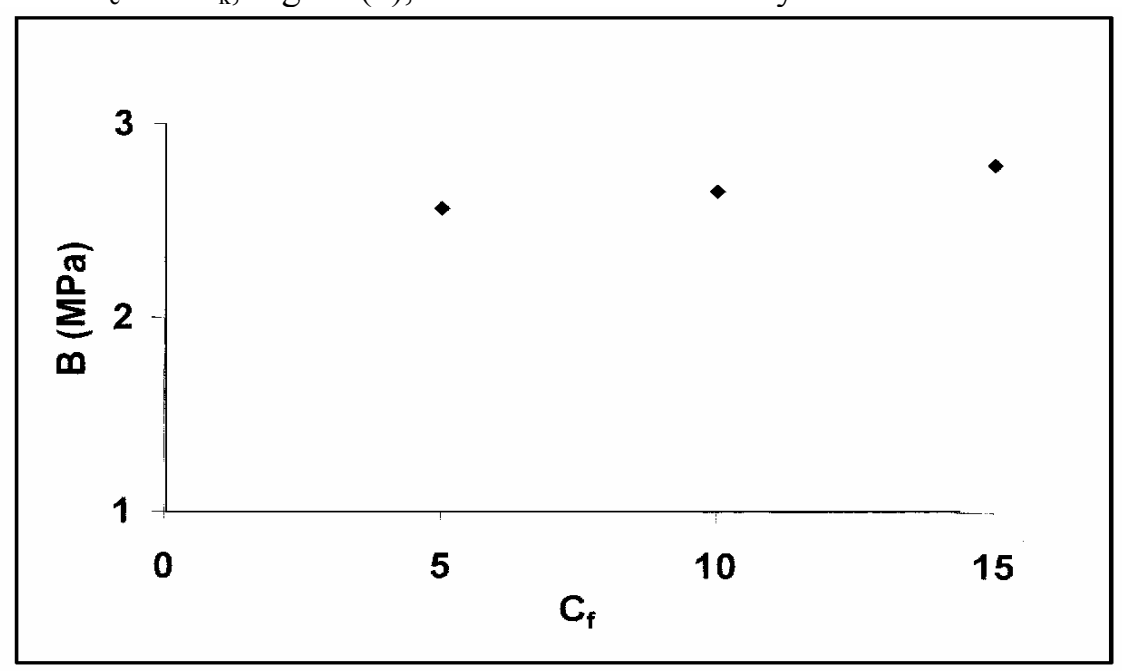

Fig. (6) The dependence of the constant B on $C_{f}$

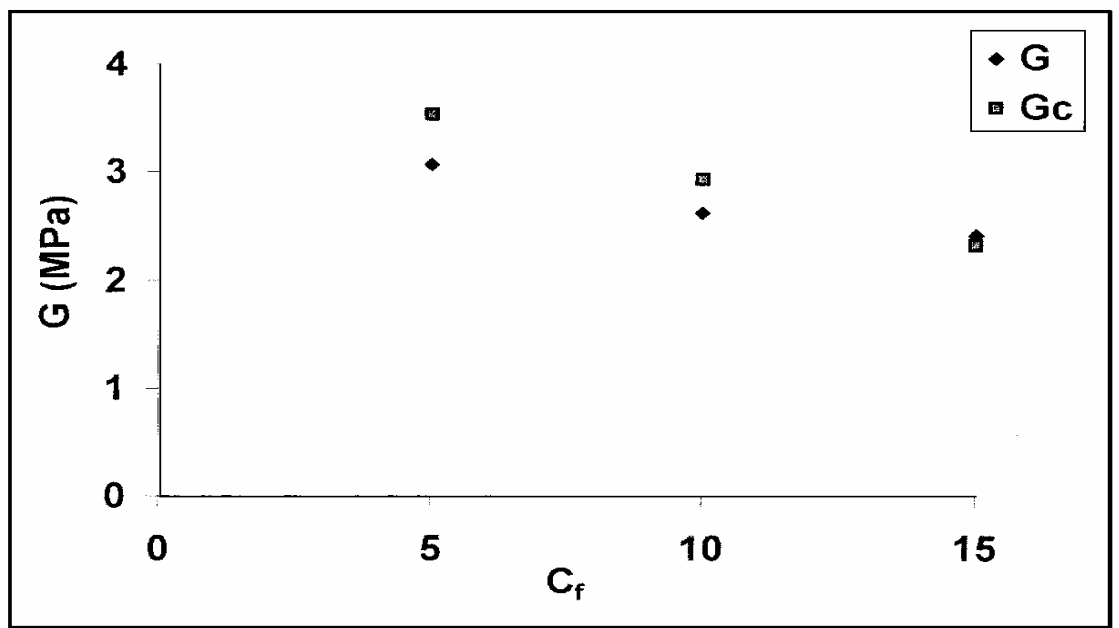

Fig. (7) The variation of $G$ as a function of foaming agent concentration, $C_{f}$, at $30^{\circ} \mathrm{X} v v \delta \varepsilon \rho \chi 0 \mu \pi \rho \varepsilon \sigma \sigma \iota v$. 


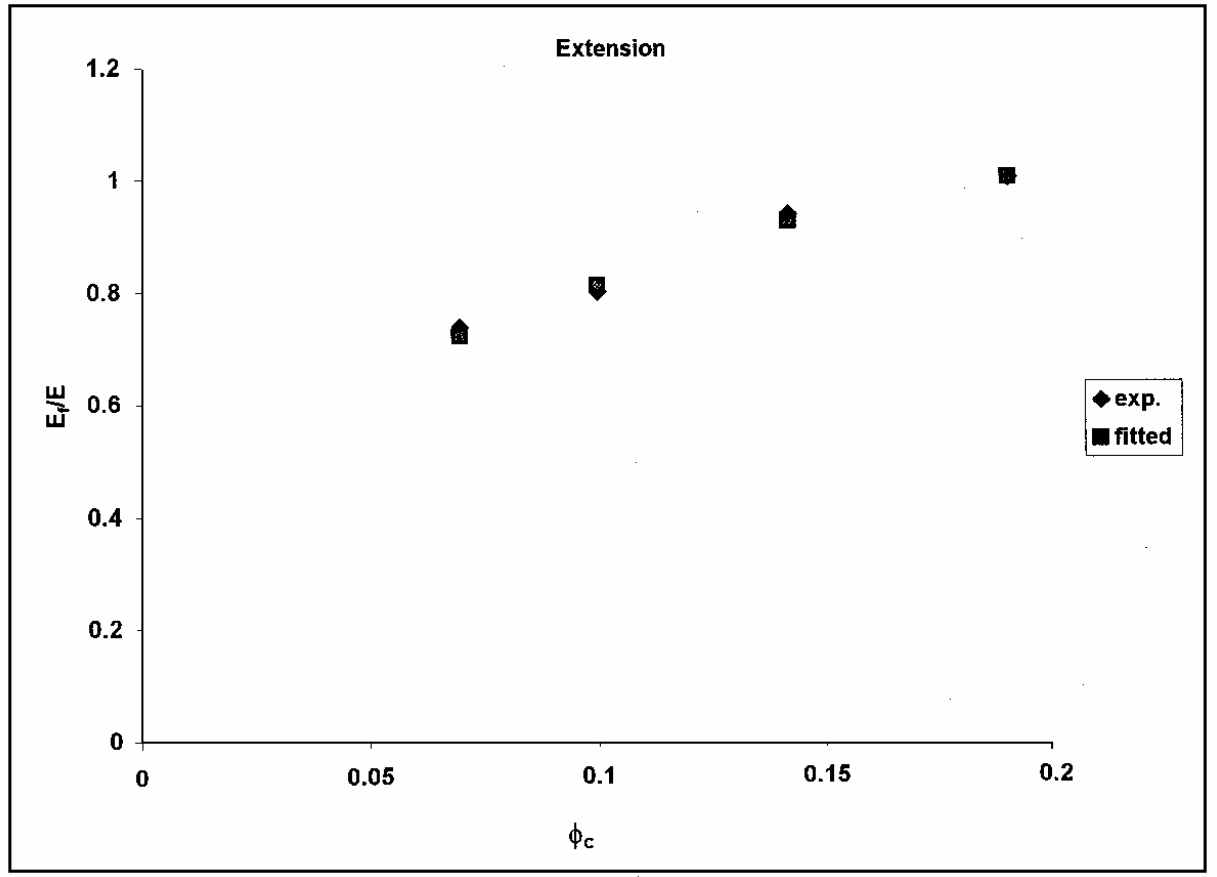

Fig. (8) The variation of the relative modulus, $\mathrm{E}_{\mathrm{f}} / \mathrm{E}_{\mathrm{VS}} \phi_{\mathrm{C}}$ in extension.

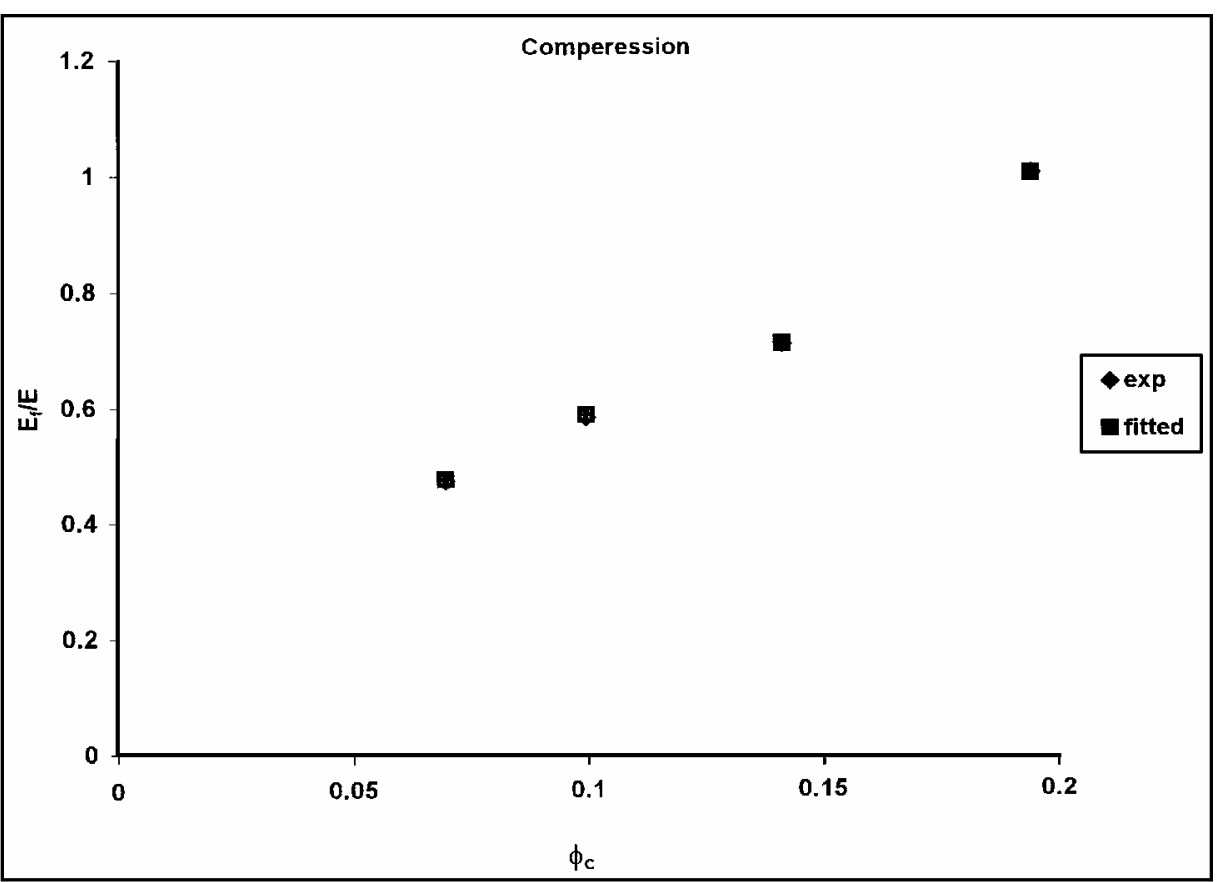

Fig. (9) The variation of the relative modulus, $E_{\mathrm{f}} / \mathrm{E}_{\mathrm{VS}} \phi_{\mathrm{C}}$ in comperession. 
Guth [25] had quoted an empirical equation that relates the shape factor for carbon black aggregate, $f$, to the relative modulus of elasticity of foamed samples, $\mathrm{E}_{\mathrm{f}} / \mathrm{E}$, as follow:

$$
\mathrm{E}_{\mathrm{f}} / \mathrm{E}=1-0.67 f \phi_{\mathrm{c}}-1.62 f^{2} \phi_{\mathrm{c}}{ }^{2},
$$

$f$ values were obtained from iteration method (Fig. $8 \& 9$ ) and are tabulated in Table (3).

Table (3): The deduced values of (f) in extension and compression.

\begin{tabular}{|c|c|c|c|}
\hline $\mathrm{C}_{\mathrm{f}}$ & $\phi_{\mathrm{c}}$ & $f$, Extension & $f$, Compressio \\
\hline 0 & 0.19 & 0.01 & 0.01 \\
\hline 5 & 0.14 & 1.20 & 0.9 \\
\hline 10 & 0.10 & 1.95 & 2.3 \\
\hline 15 & 0.07 & 3.20 & 3.8 \\
\hline
\end{tabular}

The calculated shape factor was found dependent on the foam concentration. As foaming agent is increased, the shape factor increases, indicating a change of shape from a rod like to an ellipsoidal, passing through a spherical shape.

\section{Conclusion}

Foamed EPDM rubber with density as low as $0.42 \mathrm{~g} / \mathrm{cm}^{3}$ could be obtained by an easy and simple technique. The analysis of the stress-strain data of foamed EPDM is based on the assumption that the foaming agent causes carbon dilution in the matrix. All measured mechanical parameters were found decreasing as foaming agent and/or the temperature is increased..

The obtained apparent shear modulus values were found perfectly coincide with the values obtained from the continuum mechanics theory for compressible material.

The calculated shape factor was found dependent upon the foam concentration. As foaming agent is increased, the shape factor increases, indicating a change of shape from rod like to ellipsoidal, passing through a spherical shape. 


\section{References}

1. Kiatkamjornwong $\mathrm{S}$, Thinakorn $\mathrm{S}$ and Tosa Korn Plast. Rubber Comp. 29:(4) 177, 2000.

2. Sompatsompop N Cell. Polym. 17: (2) 63, 1998.

3. Guriya K.C, Bhattachariya A K and Tripathy D. K. Kaut. Gumm.; Kunstst. 51: (2) 134, 1998.

4. Guriya K.C, Bhattachariya A.K. and Tripathy D. K. Polym. 39: (1) 109, 1998.

5. Guriya K.C.and Tripathy D.K. J. Appl. Polym. Sci. 62: (1) 117, 1996.

6. Guriya K.C.and Tripathy D. K. Plast. Rub. Compos. Pro. 23:(3) 193, 1995.

7. Shuler S. F, Binding D. M. and Pipes R. B. Polym. Compos 15(6) 427, 1994.

8. Dutta A and Cakmak M Rub. Chem. Tech.65:(4) 778, 1992.

9. Guriya Krishna Ch., Bhattachariya A.K., and Tripathy D.K.; Polymer 39, 1, 109, 1997.

10. El-Lawindy A.M.Y. Appl. Phys. Commun. 13 256, 1996.

11. Abdel-Bary E.M. Hassan H H, El-Lawindy A. M. Y. Abu-Assy M K, and El-Tantawy F.K. Polym. Int. 371, 1993.

12. El-Lawindy A. M. Y. Abu-Assy M. K. El-Tantawy F. K. Hassan H. H. and Abdel-Bary E. M. Egypt. J. Solids 19:(1) 1996

13. El-Lawindy A. M. Y. and El-Giziri S. B. J. Phys. D:Appl.Phys. 33 1894, 2000.

14. Killian H. Chem. Macromol. Symp. 30 169, 1989.

15. Smallwood H. M J. Appl.Phys.15 758, 1944.

16. Fuand F. S. and Mark J E J. Polym. Sci. 26 2229, 1988.

17. Joye D. D. J. Apply. Polym. Sci. 47 345, 1993.

18. Treloar L. R. G. The Physics of Rubber Elasticity, Oxford University Press, London, 1975.

19. Green A.E. and Zerma W. Theoretical Elasticity, Clarendon press, Oxford, 1954.

20. Green A.E. and Adkins J.E. Large elastic deformation and Non-linear Continuum Mechanics, Clarendon press, Oxford, 1960.

21. Rivlin R.S. in Rheology,. Vol 1, F.R.Eirich, Ed., Academic Press, New York, Chapter 10, 1956.

22. Mooney M. J. Appl. Phys. 11 582, 1940.

23. Rivlin R.S. and Saunders D.W. Trans. Faraday Soc., 48, 200, 1952.

24. Treloar L. R. G, Trans. Faraday Soc., 40, 59, 1944.

25. Guth E. J. Appl. Phys., 16, 20, 1945. 